\title{
Stepping out of the shadows: Allied health student and academic perceptions of the impact of a service-learning experience on student's work-readiness and employability.
}

\author{
Debra Jones $^{1}$, Lindy McAllister ${ }^{2} \&$ David Lyle $^{1}$ \\ debra.jones1@health.nsw.gov.au; lindy.mcallister@sydney.edu.au; \\ David.Lyle@health.nsw.gov.au \\ ${ }^{1}$ Broken Hill University Department of Rural Health, University of Sydney; ${ }^{2}$ University of \\ Sydney
}

\begin{abstract}
Universities, health services and health students have a vested interest in the development of work-ready graduates to improve employment prospects, standards of practice and healthcare outcomes. Work integrated learning supports the transition of theoretical knowledge into professional practice, thus preparing students for their work following graduation. The positive impact of practice experiences on work-readiness and employability is largely assumed. This paper describes the impact of participation in a rural Australian service-learning program on student and academic perceptions of work-readiness and future employability. Qualitative data was gathered from allied health students who participated in inter-professional focus groups and allied health academics who participated in individual interviews. The findings indicate that students were challenged in transitioning from being observational or highly directed learners, described as [being in the] 'shadows' or 'shadowing', to semi-autonomous healthcare providers. Participants reported enhanced perceptions of future employability through 'real work' experiences and identified broader program implications for universities and students. Based on participant experiences, service-learning, a relatively new educational pedagogy in rural health education in Australia, may provide universities, health services, and students with an alternative to acute hospital placements in the development of work-ready attributes for new graduate allied health practitioners.
\end{abstract}

Key words: Work integrated learning, work-readiness, inter professional learning, service learning

\section{Introduction}

Work integrated learning (WIL) experiences in rural and remote (referred to as rural throughout this paper) locations are a significant health workforce development strategy (HWA, 2013b). Students who are exposed to positive WIL experiences are more likely to consider rural practice post-graduation (HWA, 2013b, Deaville \& Grant, 2011). These experiences include clinical, fieldwork and service-learning placements that support student acquisition of work-readiness attributes aligned to health industry expectations, including autonomous and inter-professional practice (IPP) (Smith, Ferns, \& Russell, 2014; Nisbet, Lee, Kumar, Thistlethwaite, \& Dunston, 2011). Barriers exist nationally and in particular in rural locations, in the provision of WIL experiences. Such barriers include curriculum and 
educational responsiveness to rapidly changing health care environments, staffing reductions within health care settings (Rodger, Webb, Devitt, Gilbert, Wrightson, \& McMeeken, 2008), existing rural workforce shortages (HWA, 2013b), high work demands for health professionals and limited placement capacity (Spiers \& Harris, 2015; HWA, 2013b). Occurring in tandem with these barriers is the increased demand for placement growth to respond to increased student numbers needed to address national health workforce shortages (HWA, 2013a). These factors have contributed to the emergence of servicelearning models that extend placements into community-based settings (McAllister, Paterson, Higgs, \& Bithell, 2010) and which can serve dual purposes: expansion of placement capacity and enhanced accessibility to health care through the alignment of student learning to service provision for populations with high unmet health needs (Eyler \& Giles, 1999). Despite the growth of WIL opportunities, and specifically service-learning in rural Australia, there is limited evidence of the impact of participation in these models on student learning outcomes, academic institutions and community agencies (Smith et al., 2014; Steinberg, Bringle, \& Williams, 2010).

The purpose of this qualitative study was to explore the impact of participation in a rural community-based inter-professional service-learning (CBISL) program for students, academics and community agencies. The program aligned the learning requirements of final year occupational therapy (OT) and speech pathology (SP) students to the provision of services to address the unmet developmental needs of school children residing in far west New South Wales (NSW), Australia.

\section{Context}

\section{Rural health workforce development and work integrated learning}

Rural communities face complex challenges in the recruitment and retention of health professionals (HWA, 2013b). Health workforce shortages impact on the type and intensity of services available (DoHA, 2010) and allied health professionals are particularly underrepresented in rural locations (AHPA, 2013; Spiers \& Harris, 2014). The provision of rural experiences for students is a significant strategy in addressing these health workforce shortages (HWA, 2013b). Evidence suggests that where students are exposed to positive experiences they are more likely to consider rural practice in the future (Deaville \& Grant, 2011).

WIL includes clinical, fieldwork and service-learning placements that support students in the acquisition of work-readiness attributes for graduate practice, including autonomous and IPP (Smith et al., 2014; Nisbet et al., 2011). Generic attributes include clinical reasoning, adaptability, time management, planning and organisation, self-confidence, independent working and IPP (Jackson, 2010; Smith et al., 2014). IPP attributes are acquired when students work collaboratively in professional teams to accomplish shared goals that improve healthcare outcomes (Freeth, Hammick, Reeves, Koppel, \& Barr, 2005). The acquisition of generic and inter professional skills and student capacity to demonstrate these to potential employers is increasingly being linked to enhanced employment outcomes for Australian graduates (Smith et al., 2014).

Despite the benefits of WIL, as mentioned above, barriers exist nationally and rurally in the provision of quality WIL experiences (HWA, 2013a). Rodger and colleagues (2008) broadly describe these barriers as a lack of curriculum and education responsiveness to rapidly changing healthcare environments and decreased placement capacity resulting from workforce reductions. In rural locations, workforce shortages, across a range of disciplines, high work demands and limited placement capacity in hospital settings, all impact on student ability to access rural WIL opportunities (Spiers \& Harris, 2014; HWA, 2013b). Health Workforce Australia (HWA, 2013b) also identified that rural locations are being confronted with increasing demands to extend placement capacity in response to the growth in health

Jones, D., McAllister, L., \& Lyle, D. (2015). Stepping out of the shadows: Allied health student and academic perceptions of the impact of a service -learning experience on student's work readiness and employability, Journal of Teaching and Learning for Graduate Employability 6(1), 66-87. 
student numbers needed to address national health workforce shortages, contributing to the emergence of community-based WIL models (Rodger et al., 2008, McAllister et al., 2010).

\section{Community-based service-learning}

In rural locations service-learning is being drawn on by University Departments of Rural Health (UDRH), key stakeholders in Australian rural health workforce development (Mason, 2013), to establish models that transition students from the patient bedside into community settings. Service-learning is concerned with balancing student learning and service recipient outcomes (Furco, 1996) through the alignment of student learning to the provision of services to populations with identified unmet health needs (Eyler \& Giles, 1999; Jacoby, 2003), characteristics reflected in rural Australia. Service-learning models expose students to a range of population health needs, diverse community members, alternative service delivery models, complex problems and community partnerships (Jacoby, 2003). Servicelearning extends learning through the formation of community-academic-student partnerships (Furco, 1996; Seifer, 1998).

The goals of service-learning partnerships go beyond addressing the learning needs of individual students by focusing on civic engagement as a conduit to achieving learning outcomes. Service-learning engages community partners in student professional, technical and civic development (Cashman \& Seifer, 2008). A service-learning approach to experiential learning (Kolb, 1984; Furco, 1996) links theoretical knowledge acquired within curricula to the 'real-life' application of knowledge (Titchen \& Higgs, 2001; Cashman \& Seifer, 2008). This alignment enables students to engage in learning that can include illdefined problems that occur within 'real' community contexts which cannot be replicated in hospital or university settings (Keys, 1994).

\section{A rural community-based inter-professional service-learning program}

The Allied Health in Outback Schools Program (AHOBSP) commenced in far west NSW in 2009 and was informed by the principles of service-learning and experiential learning. The program is underpinned by a cross-sector partnership between school education and health service stakeholders, the Broken Hill UDRH (BHUDRH) and The University of Sydney Faculty of Health Sciences. Program objectives include addressing unmet allied health needs of children, expansion of regional placement capacity through extension into nontraditional community settings, and exposure of students to alternative population health practices (Wylie, McAllister, Marshall, \& Law, 2014), with intent to influence student place of practice post-graduation (Deaville \& Grant, 2011).

Serial inter-professional, OT and SP, student cohorts, (i.e., new cohort of final year OT and SP students each school term), undertake placements across the four school terms. Students participate in an intensive five day orientation program and weekly professional reflection sessions facilitated by the BHUDRH with services being delivered in pre-schools and primary school settings. Students draw on the work of previous cohorts to inform service activity creating service continuity. Students, with same-discipline, as well as interprofessional supervision, from qualified OTs and SPs, provide screening, assessment and therapy as inter-professional groups for children with mild to moderate developmental delays. Children identified with complex delays are referred to hospital clinicians for further assessment. Supervision is provided through scheduled face-to-face contact throughout the students' 'working week' and via email, SMS and telephone. Approximately 150 pupils access these services annually. Service delivery takes a population health approach (Kindig \& Stoddart, 2003) in response to the needs of school children, parents, and teachers and includes individual, small group, and whole of class sessions (Wylie et al., 2014).

In each school term, four OT students and six SP students engage with three regional communities and 12 school campuses. A total of 24 SP and 16 OT students are placed

Jones, D., McAllister, L., \& Lyle, D. (2015). Stepping out of the shadows: Allied health student and academic perceptions of the impact of a service -learning experience on student's work readiness and employability, Journal of Teaching and Learning for Graduate Employability 6(1), 66-87. 
annually representing significant growth in regional allied health placement capacity (Jones et al., 2015). Term-specific documentation guides student service planning and delivery. Students develop individualised pupil therapy plans and handover documents identifying successful pupil engagement strategies, assessment and therapy outcomes. Therapy plans then guide parental and teacher involvement in home and ongoing class-based interventions (see Jones et al., 2015 for more information).

Students participate in structured mid and end of placement program evaluations facilitated by an independent researcher, informing program improvement and adaptation. However no formal evaluation had been undertaken on the impact of participation in this program for allied health students, academics, community leaders, facilitating agencies and service recipients. Limited evidence exists, especially within the rural Australian context, on the efficacy of service-learning for these key stakeholders (Steinberg et al., 2010; Frenk et al., 2010; Kramer \& Usher, 2011; Smith et al., 2014). As an emerging health education strategy in rural Australia additional research is required that explores these outcomes.

\section{The Study}

The research aims of this study were to provide a deep and holistic understanding of the impact and outcomes of participation in the AHOBSP for key stakeholders, ensuring this exploration was informed by multiple stakeholder perspectives (Creswell, 2007). The study was qualitative in design, explored the experiences of community leaders; pre-school and primary school principals, senior managers from local facilitating agencies; one based with the UDRH and one with school education, SP and OT students, and academics engaged in the development and delivery of the program.

Due to the breadth of study findings this paper reports on student and academic outcomes, specifically those associated with perceptions of student work-readiness skills acquisition and future employability. Additional student, academic and community experiences are described in subsequent papers.

\section{Method}

Low risk ethical approval was obtained from the University of Sydney Human Research Ethics Committee (approval number 2014/178), NSW Department of Education and Communities (SERAP approval number 2014117), Catholic Education Office and La Trobe University (written approval).

\section{Participants}

Academics and OT and SP students were purposefully selected based on their role in program development and delivery. Participants were contacted through work and student university email accounts. An introductory email including information sheets and consent forms was sent by an independent administration officer to one student cohort and two academics. The email provided contact details of the lead investigator for additional study information. Signed consent forms were returned to the administration officer. All data was collected in the latter half of 2014.

The entire student cohort, OT 4 and SP 6, undertaking their placement in one school term in 2014, consented to participate in one of two face-to-face focus groups. Face-to-face focus groups (FGs) were held onsite at the BHUDRH. Students represented two different universities. Two allied health academics, one rurally located with direct responsibility for student supervision and one metropolitan, with a strategic program role, consented to participate in individual semi-structured interviews, face-to-face for the rural academic and via teleconference for the metropolitan academic. 
Student FGs were considered appropriate given the shared experience of the program, time restrictions associated with placement duration and levels of comfort during data collection (Patton, 2002). Students were purposefully allocated to each FG to ensure an even distribution of OT and SP students, reflecting the inter-professional placement (two OT and three SP students in each FG). Both FGs ran for approximately 60 minutes. An independent qualitative researcher facilitated both sessions using a prepared schedule of questions developed from previous cohort evaluations ( $n=12$ sessions) and study aims. Questions focused on:

1. Factors that influenced program participation and student pre-placement understanding of the program.

2. Comparison of the placement to previous placement experiences.

3. Learning impacts associated with program participation.

4. How students would describe the placement to their non-participating peers.

5. Understanding of program aims.

6. Recommendations for program improvement and future directions of the program.

Follow up questions were asked to encourage greater participant feedback. FG sessions were digitally recorded and transcribed manually. Allied health students were de-identified by discipline and university in the transcripts due to small participant numbers and placement location to ensure confidentiality. Participants were allocated FG and student numbers: Focus Group 1 Student 1 - FG1:S1, Focus Group 2 Student 2 - FG2:S2 and so on.

\section{Semi-structured individual interviews}

Individual academic interviews were selected due to variations in program roles, differing levels of seniority and geographical separation. Each interview ran for approximately 50 minutes. The same independent qualitative researcher facilitated both interviews using a prepared schedule of questions developed from previous academic feedback and the study aims. Questions focused on:

1. Factors that influenced program participation and participant role in program development and delivery.

2. Impact of participation in the program on participant approach to education delivery, practice and strategy.

3. How the academics would describe the program to external community and university agencies.

4. Understanding of program aims.

5. Suggestions for program improvement and future directions of the program.

Some variation existed between the questions and follow up questions asked of the academics reflecting their operational and strategic program roles. Individual interviews were digitally recorded and transcribed manually before being provided to participants for verification. Academic participants were de-identified by discipline to ensure their confidentiality based on small participant numbers and allocated identifiers, RA for Rural Academic, and MA for Metropolitan Academic.

\section{Data analysis}

Data was analysed using an inductive, content-sensitive approach (Patton, 2002). The lead researcher repeatedly listened to digital recordings and read and re-read the transcripts, to become deeply familiar with the audio and texts. Coding was conducted using a process of constant comparative analysis (Miles, Huberman, \& Saldana, 2014). Data was manually 
coded based on the researchers' desire to avoid distancing themselves from the data (Creswell, 2007). The process began with identification and coding of words or phrases that captured key meanings. These codes were then grouped and re-grouped into a smaller number of categories. Coding and categorisation was constantly compared within, and across, transcripts to ensure consistency in development, application and refinement of student and academic codes and categories. Categories were collapsed into overarching themes until all codes and categories were accounted for (Patton, 2002). This approach enabled the researchers to explore, in-depth, student and academic perspectives.

Data interpretation was critically appraised and verified by expert qualitative researchers with a depth of experience in allied health and primary health care professional education. The lead and expert researchers independently coded two transcripts using the same process. These codes were then compared, explored, and refined with the identification of key themes and sub-themes. The remaining texts were coded independently by the lead researcher. Trustworthiness of the analysis was enhanced through checking processes: referential adequacy through recording and verbatim transcription of focus group and individual interview data, checking of transcripts against the recordings to ensure accurate transcription and member-checking of individual interview transcripts (Creswell, 2007). In order to ensure interpretation process trustworthiness, a clear and transparent record was maintained of the hand coding process. Rigor was further enhanced by the inclusion of direct participant quotes to illustrate the five identified themes, subthemes and subsections (Creswell, 2007) as outlined in Table 1.

Table 1: Themes, Subthemes and Subsections.

\begin{tabular}{|c|c|}
\hline Theme & Subthemes (numbered) and subsections (dot points) \\
\hline $\begin{array}{l}\text { 1. Challenges in transition to } \\
\text { service-learning }\end{array}$ & $\begin{array}{l}\text { 1. Students as supernumerary or inactive in previous learning } \\
\text { experiences: Shadows } \\
\text { 2. Student as observer/highly directed learner: Shadowing } \\
\text { 3. Fragmented and specialist exposure to care delivery }\end{array}$ \\
\hline 2. Context of care & $\begin{array}{l}\text { 1. Rural context } \\
\text { 2. Community-based population health practice }\end{array}$ \\
\hline 3. Work-readiness attributes & $\begin{array}{l}\text { 1. Relationships } \\
\text { - Service-Learning } \\
\text { - } \text { Acommunity } \\
\text { - Student-Program } \\
\text { 2. Learning planning and organisation skills } \\
\text { 3. Clinical reasoning } \\
\text { - Supervision approach } \\
\text { - Peer learning } \\
\text { 4. Inter-professional practice } \\
\text { 5. Self confidence }\end{array}$ \\
\hline 4. Employability & $\begin{array}{l}\text { 1. Perceptions of previous student employment outcomes } \\
\text { 2. Enhanced skills acquisition } \\
\text { 3. Employer implications }\end{array}$ \\
\hline 5. Program implications & $\begin{array}{l}\text { 1. University implications } \\
\text { - Curriculum development } \\
\text { - Model transferability } \\
\text { 2. Student implications } \\
\text { - Impact on care delivery } \\
\text { - Longer placement durations }\end{array}$ \\
\hline
\end{tabular}

Jones, D., McAllister, L., \& Lyle, D. (2015). Stepping out of the shadows: Allied health student and academic perceptions of the impact of a service -learning experience on student's work readiness and employability, Journal of Teaching and Learning for Graduate Employability 6(1), 66-87. 
- Rural practice

- Return to previous supervision approaches

\section{Results and Discussion}

Data analysis identified five themes, associated subthemes and a number of subsections. These are each elaborated and followed by a brief discussion.

\section{Theme 1: Challenges in transition to service-learning}

Participants identified a number of factors that impacted on student capacity to transition from previous practice experiences to a semi-autonomous service-learning role. Students and the RA used terms such as 'shadow', FG1:S2, to describe student preference to be supernumerary or inactive in initial stages of placement, and 'shadowing', FG2:S1, to describe previous supervision approaches where students were an observer or highly directed learner. Three subthemes are now described using participant comments, followed by a brief discussion.

Subtheme 1: Students as supernumerary or inactive in previous learning experiences: 'Shadow' role.

Student participants described previous practice experiences where they were inactive in the learning environment as having ...just had observational practicums (FG1:S3). Consequently some students viewed their participation in the service-learning program, particularly when compared with these previous experiences, as being:

...thrown off the deep end. (FG2:S3)

... beneficial for us to be thrown in the deep end and get that experience. (FG1:S3)

However, other students did not see this as a benefit reflecting a preferred supernumerary approach:

I didn't have that opportunity to shadow [the supervisor] for a short period of time prior to [engaging in service delivery], it caused me a little bit of anxiety. (FG1:S2)

Student perceptions of how academics regarded the benefits of the program included:

Our placement coordinator made an emphasis on the advantages of student-led placements. (FG1:S3)

The tasks that students undertake in their practice experiences are considered crucial for quality learning outcomes (Herrington \& Herrington, 2006). Smedley and Morey (2010) identified students' preference to be active participants in practice settings and that a lack of participation impeded student confidence, competence and learning outcomes. Student experiences of being inactive in their previous placements and preference for opportunities to remain supernumerary, or to 'shadow', in the initial stages of placement, potentially reflect a lack of semi-autonomous practice in previous learning experiences. This may have contributed to student perceptions of 'being thrown in the deep end', being influenced by program expectations of higher levels of semi-autonomous student practice.

Subtheme 2: Student as observer or highly directed learner: 'Shadowing' role.

A number of students commented that in previous practicums they had passively followed their supervisor. The concept of 'shadowing' was described by students as being associated with activities where they were heavily directed by their placement supervisors:

In other placements you just do what you're told and get on with it (FG1:S3). 
We've always had supervisors shadowing us, being like do this, do that. (FG2:S1)

One student commented that being an observer only was appropriate for them:

My learning style is to observe something. It's simpler when you can see it than when you have to work it out for yourself. (FG1:S3)

The RA identified implications of this shadowing approach to supervision on student development of work-readiness attributes:

Those work ready skills are difficult to develop in other placements where there is that shadowing level of supervision.

Exposure of students to discipline role models and professional experts enhances students' understanding of how 'real' practitioners behave in 'real' healthcare contexts (Herrington \& Herrington, 2006). When students are not actively engaged by supervisors in understanding practice rationales and healthcare approaches they are less likely to be able to model and contextualise 'real-world' service provision (Herrington \& Herrington, 2006). Students, who are exposed to 'shadowing', especially in the final stages of their degree where higher levels of autonomous practice can be a discipline expectation, may struggle to develop practice competence and confidence. Shadowing may also result in students devaluing their contribution to health care delivery and client outcomes.

Subtheme 3: Fragmented and specialist exposure to care delivery

Students described prior experiences of fragmented and specialised exposure to healthcare delivery, challenging their ability to conceptualise holistic client care:

In some of the other placements l've had in the past it's hard to put all of the pieces

together because you're only a small part of [care]. (FG2:S4)

Students described a lack of exposure to a diverse range of therapeutic activity as impacting on their ability to respond to complex and diverse health care needs experienced by pupils in the program:

I've had a lot of [specialised therapy] experience but very little [other specialised therapy] experience and this placement has predominately been around [the other specialised therapy]. I've been like, What am I doing? Am I doing this right? (FG2:S1)

Students need to be provided with experiences that enable them to understand and apply their knowledge in complex environments, in this instance a rural community-based context, so they are appropriately prepared for the 'real-world' of work. Curricula requirements and practice environments need to be responsive to contemporary heath care practice and student learning needs, providing opportunities for students to engage with diverse practice opportunities when they present themselves, supporting student capacity to comprehend and engage with complex and inter-connected components of care (Sturmberg, 2005).

\section{Theme 2: Context of care}

This theme has two subthemes: rural context and community-based population health practice.

Subtheme 1: Rural context.

The rural context was seen as contributing to participant experience, with students commenting on the connections with the community:

Part of the interest in coming here was being in the rural town and experiencing it for yourself. (FG1:S5) 
Everyone in [rural community] knows each other or has a connection at some point. (FG2:S5)

It's not like a major city where you can pass by so many people and no one talks to each other. (FG1:S3)

The RA described the deeper connectivity of the program and student learning experience within the rural context:

We sit and live in this community. We are service providers to our community and we [are] doing that through the education of students.

The authors propose that the view of Rodger and colleagues (2011) regarding a welcoming clinical environment as an indicator for quality learning experiences can be extended beyond the clinical setting to include the broader welcoming nature of host communities. Denser connecting mechanisms, within and across rural communities, create different learning environments for students influencing approaches to healthcare provision. In developing rural community-based WIL opportunities academic institutions and health professionals need to be informed about and acknowledge the importance of rural community contributions to student learning outcomes (Rodger, Fitzgerald, Davila, Millar, \& Allison, 2011).

\section{Subtheme 2: Community-based population health practice}

The five day orientation component of the program was established to support student transition to rural community-based practice. This aspect of the program was appreciated by participants as seen by the following comment:

It's getting orientated to the whole experience. You have a new placement, you're nine hours from home, you're in a new place, you're meeting new people, you're trying to explore the town, you're looking at different schools and you're going to [Outreach communities]. There's a lot on, it's great, it's just a little bit intense for the first week. (FG1:S5)

The validity of the population health approach, class-based therapy, to allied health service delivery was questioned by a student, challenging their perception of 'real' therapeutic approaches and location of therapy delivery:

I think time would be much better spent doing individual sessions rather than trying to manage an entire class. You're setting these [broader] goals. I'm starting to think, 'What should pupils be doing at this age?' That's where I'm pitching this lesson rather than focusing on therapy. It's not really therapy. (FG2:S4)

Student preparation for their WIL experience is a key curriculum dimension (Smith et al., 2014). Program orientation has been extended from two to five days in an endeavour to prepare students for their experience. Orientation includes cultural education, community tours, introduction to key program stakeholders, tours of host schools and clinical education focused on technical skills development required to enhance service delivery and pupil outcomes. A high priority is placed on supporting students in understanding the context of their placement and alternative health care approaches. Understanding contexts of care that impact on community health is essential in the provision of population healthcare. Differing social, educational, cultural and economic status experienced in rural locations creates different 'terms of reference' for communities, influencing how and where care can best be provided, including service delivery in school settings (Kindig \& Stoddart, 2003; WHO, 2010). Service-learning is concerned with broadening student exposure to diverse populations, specifically marginalised and underserved populations (Jacoby, 2003), in this instance through population healthcare delivery (DoH, 2010).

Jones, D., McAllister, L., \& Lyle, D. (2015). Stepping out of the shadows: Allied health student and academic perceptions of the impact of a service -learning experience on student's work readiness and employability, Journal of Teaching and Learning for Graduate Employability 6(1), 66-87. 


\section{Theme 3: Work-readiness attributes}

This theme contains five sub-themes: relationships, planning and organisation skills, clinical reasoning, inter-professional practice; and self-confidence and associated subsections.

\section{Subtheme 1: Relationships}

This subtheme contains four subsections associated with relationships.

\section{Subsection 1: Service-learning relationships}

The multi-layered program relationships, the connection between service and learning and the importance of time to build positive relationships were all recognised by the students:

There's a lot of support from the university, our supervisors, the hospital staff [and] community. They understand why we are here and what we are doing. (FG2:S2)

We can see we have provided a service for these pupils. We're able to achieve our own [learning] goals while we're doing it. (FG2:S1)

Students come and go. It takes time to build rapport with the [pupil]. (FG2:S1)

Seeing the pupils every day, they all remember your name. It feels really nice. It feels different to other placements in that way. (FG1:S2)

Students also described a sense of responsibility associated with their pupil relationship:

Our responsibility [when we are at 'work'] is to provide therapy for these pupils. (FG1:S2)

\section{Subsection 2: Community relationships}

Students described the friendly nature of the community and displayed insights into the social connectivity of the community:

I find everybody's so easy to talk with. (FG1:S3)

The community has that really amazing atmosphere. Everyone talks to everyone, everyone knows everyone's business and everyone's related. (FG1:S1)

The MA described their relationship with the community:

That visit to community was incredibly important in terms of my thinking. I felt ashamed of my own profession because of what had happened in the community. The level of disillusionment in the principals I found quite distressing. I came away very determined I was going to help be part of the solution.

\section{Subsection 3: Academic-student relationship}

The RA perception of their relationship with the students was collegiate:

I'm working alongside budding [discipline] so there's greater capacity between us [to deliver services].

Students discussed the depth of program knowledge of their supervisors and identified the cumulative nature of this knowledge from past student cohorts:

They just know every little bit. We do debrief every week and they have an agenda that has slowly been accumulated from previous placements. They know how we're feeling, what we're thinking. (FG2:S1) 


\section{Subsection 4: Student-program relationship}

Students demonstrated an understanding of the importance of building and sustaining trust between program stakeholders and how this trust could be detrimentally impacted upon by student approaches to relationships:

They've [program partners] worked really hard on the program so far. They've built that rapport with the teachers to gain that trust. [The community have] obviously had [services] coming in and out, inconsistent. It's up to how well the future students manage that [relationship]. (FG2:S3)

Students identified the 'student continuum' approach as a connecting relationship between serial student cohorts and program outcomes:

It's nice to see that [previous cohorts have] been doing the same thing. You just have to keep doing it so that the next person knows exactly what to do. Here in this continuum of students you really do feel like you're at least making some change [for the pupil] (FG1 S2).

Positive relationships established on placement significantly improve student learning outcomes (Hartigan-Rogers, Cobbett, Amirault, \& Muise-Davis, 2007). However there are few formally identified efforts that seek to assist students in developing effective relationships (Suchman, Sluyter, \& Williams, 2011). Relationship-centered care (RCC) is based on partnerships between individuals, communities and health care practitioners and includes an understanding that relationships occur at multiple levels, between different partners and are critical for effective health care delivery (Suchman et al., 2011). There are increasing calls for allied health professions to engage in population health approaches that are intrinsically linked to complex relationships (Miller \& Gallicchio, 2007; Wylie et al., 2014). A lack of practice experiences within community-based organisations that provide exposure to these relationships has been identified as a constraint in the provision of RCC experiences (Suchman et al., 2011). Our data supports the value of investing in the provision of these opportunities at the pre-registration level.

\section{Sub-theme 2: Learning planning and organisation skills}

Students identified a lack of previous exposure to decision making, case load management, development and implementation of therapy plans, preparation of documentation, and the preparation of new or utilisation of existing resources, as impacting on their capacity to confidently undertake these tasks within the early stages of program participation:

We always go over time. Nine times out of ten, it's 7.30, 8, 9 o'clock at night and I'm still preparing [resources]. (FG2:S1.

Just working with the resources we do have, it's been emphasised throughout the placement, 'You should try and work with what's available, use what's in the [class] room'. It has been really useful to try and do that (FG2: S4).

The MA identified the learning impact associated with the program, including time management and resource use:

It's not only time, they have to manage their learning. They need to know what they don't know and work with the resources that are available.

Students identified exposure to 'real' work experiences as impacting on their planning and organisation skills: 
You have your own caseload, you have to make your timetable, make your session plans [and] think about therapy. (FG1:S3)

Planning and organisation skills include time management, effective use of resources, collecting, analysing and organising information (DIISRTE \& DEEWR, 2013). Despite the literature identifying the importance of these skills (Smith et al., 2014) our findings suggest that students can be poorly prepared to undertake these tasks when their responsibility for these tasks in professional practice settings has been limited. Accessibility of resources in rural locations is frequently less than that experienced in metropolitan practice and health professionals are required to think innovatively in the identification of, and access to, alternative resources to enable the delivery of therapy.

\section{Sub-theme 3: Clinical reasoning}

This subtheme contains three subsections: supervision approach, peer learning and scope of experience.

\section{Subsection1: Supervision approach}

The supervision approach of the program was described as contributing to the development of higher levels of autonomy in professional and technical decision making:

Because there isn't that constant supervision I was constantly [asking myself] 'Am I doing this right? Is this okay? Am I pitching it at the right level? Did I use the right feedback? Am I using the right tools?' Personally that was quite a challenge doing that on my own [initially] but now [it's okay]. (FG2:S1)

\section{Subsection 2: Peer learning}

The RA identified the role of peer learning as an additional modality to support the development of clinical reasoning skills:

I talk more formally with the students in debrief. You don't go to your supervisor first in the workplace, that's not the first place you go if you need help, you go to your peers.

The impact of peer learning was also discussed by the students:

To be able to manage our own case load and still have the support there to ask [the supervisor] questions, find out if we're doing the right thing, have the other students as well, to discuss different aspects [of therapy]. (FG2:S2)

The MA identified peer learning as a workplace skill:

They learn how to work with their peers, maximise their learning. That's a great workplace skill to have.

\section{Subsection 3: Scope of experience}

Students identified program participation as impacting on their clinical reasoning skills, describing skill acquisition in information processing, analysis, decision making and resultant implications for client care:

You have to think about therapy, how and why, the clinical reasoning behind why you are doing that type of therapy. That thought process is going on. 'Why are you doing what you're doing and how is it going to help a client?' (FG1:S3)

Student capacity to understand holistic approaches to service delivery through exposure to a broad range of therapy approaches and continuity of client care was described: 
I think [the program] makes [therapy delivery] make more sense. You have a much more holistic understanding of the whole [process]. (FG2:S4)

Educational institutions may struggle to challenge students in developing clinical reasoning (Sharp et al., 2013; Arum \& Roksa, 2011) due to a lack of 'real' context (Durning, Artino, Pangaro, van der Vleuten, \& Schuwirth, 2011). Health care practice is underpinned by clinical reasoning and a failure of adequate clinical reasoning can have negative impacts on client outcomes of care (Norman, 2005). The development of clinical reasoning skills for allied health students has been identified as being essential in enabling students to gather, analyse and process information to inform logical decision making across health care contexts (McAllister \& Rose, 2008). The provision of higher levels of autonomous practice, within a framework of safety, and peer learning for senior students has been identified as contributing to the development of clinical reasoning skills (Smith et al., 2014, Kuipers, Pager, Bell, Hall, \& Kendall, 2013). Service-learning is also viewed as inherently promoting clinical reasoning attributes through exposure to direct service provision (Steinke \& Fitch, 2014).

\section{Sub-theme 4: Inter-professional practice}

Study participants identified the importance of accessing WIL IPP experiences. The RA and students commented as follows:

Inter-professional practice was [talked about] at university. I hadn't had a go at [interprofessional practice] at university.

Inter-professional education, you don't really get, you never get that. (FG1:S2)

The MA identified the importance of IPP experiences for students at their institution:

A goal of our faculty is to make sure our students have at least one genuinely interprofessional placement. For many of our students this [program] will be the one and only true inter-professional placement they have.

The students provided examples of sharing inter-professional knowledge in approaches to therapy planning and to enhance therapy delivery:

You know what the other discipline activity is, you speak to them before and after therapy, you talk to them after school and you plan therapy together. (FG1:S2)

Maybe something's working, you've got the same pupil and something's working during therapy with this pupil in your discipline so you pass it onto the other discipline and say try this out. (FG1:S3)

Health industry expectations for new graduates include the acquisition of a breath of knowledge, skills and experiences that will enable them to locate themselves as valuable IPP team members (Nisbet et al., 2011). The benefits of IPP include positive interactions across different professions, enhanced collaboration between professions, development of mutual trust, decreased service duplication, and improved health care safety and client satisfaction (Nisbet et al., 2011). Despite IPP being considered standard practice in Australian health care settings findings from this study support the findings of Howell, Devine and Prostman (2004) that students may receive little or no formal IPP experience during their training. There is a need to embed meaningful IPP experiences within Australian health practice settings to ensure new graduates are prepared for contemporary healthcare practice. Due to the breadth of findings associated with IPP this sub-theme will be explored in greater detail in a subsequent paper.

\section{Sub-theme 5: Self-confidence}

Students identified enhanced self-confidence in their skills associated with program participation: 
As a clinician coming into our second last placement it's very beneficial to be at least feeling confident in this area. I'm feeling better. You've got more skills. It's good to be finally feeling like that coming up to graduation. (FG1:S5)

Students discussed the impact of semi-autonomous practice as contributing to their trialling and implementation of alternative therapeutic approaches:

The independence, going and doing some therapy, that didn't work so well, what can I do next time? There's a lot of professional reflection. (FG1:S5)

Practice experiences play a key role in the development of professional self-confidence (Rodger et al., 2008). Supportive learning environments, with appropriate levels of supervision and safety, can enable students to learn from their mistakes contributing to learning opportunities that require them to explore alternative approaches to therapy delivery that enable the alignment of therapy to individual client need (Plack, 2008). Building student confidence to practice independently is a key learning outcome as students near completion of their degree (Newton, Billet, Jolly, \& Ockerby, 2009a).

\section{Theme 4: Employability}

This theme consists of three subthemes, perceptions of previous student employment outcomes, enhanced skills acquisition and employer impact.

\section{Subtheme 1: Perceptions of previous student employment outcomes}

Knowledge of employment outcomes of past student participants who were seen to have gained employment first on graduation were discussed:

The students who had done the placement [previously] were actually the first to get jobs. I think it had a lot to do with the fact that it's so student-driven. The employers really liked that. Makes us more work ready. (FG2:S1)

Enhancing employability outcomes is considered integral to degree programs (Jackson, 2010). WIL experiences are considered a significant strategy in the development of workreadiness attributes that enhance graduate employability (Jackson, 2010; Smith et al., 2014). Participation in the program was perceived by students as an opportunity to develop work-readiness attributes that would be considered desirable by potential employers. Additional research is required on the employment outcomes of program participants, including industry perceptions of participant characteristics that may influence employer selection, to validate these perceptions.

Subtheme 2: Enhanced skills acquisition

The RA shared their perception of enhanced skills acquisition, thereby facilitating transition into the workplace for students in comparison to non-participating peers:

[These students] do have skills that other students don't, a whole lot more.

I think [the program] aims to achieve service-giving skills in the new graduates and prepare them in a way they should be prepared.

Students shared this perception stating that their skill level was enhanced by more realistic [work] (FG2:S3), that would:

Really set us up for working, going into the workplace (FG2:S2).

Developing graduates with work-readiness attributes that are considered valuable by employers is a key objective of WIL strategies (Skills Australia, 2010). WIL is viewed as supporting students in the development of skills that have the potential to enhance their employment outcomes (Smith et al., 2014). Health graduates who: possess a range of work-

Jones, D., McAllister, L., \& Lyle, D. (2015). Stepping out of the shadows: Allied health student and academic perceptions of the impact of a service -learning experience on student's work readiness and employability, Journal of Teaching and Learning for Graduate Employability 6(1), 66-87. 
readiness skills may experience a smoother transition into the workplace compared with graduates lacking such skills (Walker et al., 2013, p.116).

\section{Subtheme 3: Employer Implications}

The RA identified the importance of their role in describing student program experiences to potential employers when acting as a student referee: The employers are not familiar with the program and they say, 'Oh wow, that's fantastic'. While many of the students saw enhanced employability as an outcome of their service-learning placement, not all students did. One student questioned whether the experience in a community-based setting would prepare them for a hospital position:

I wonder whether this placement is preparing me for the workplace. Say I go into a hospital next year, has this placement actually equipped me to do that because I have that lack of traditional placement in a hospital. (FG1:S2)

The MA also questioned whether the students who had participated in the program had enhanced employability potential in comparison with non-participating peers:

I don't think we know whether they're better prepared. We don't have a direct comparison with other types of placements. I know [the program is] incredibly helpful.

There is an increasing call at the national level for the integration of population health and primary health care practice into health care education and service delivery (DoHA, 2010). Frenk et al. (2010) stated that health professional education has not responded effectively to contemporary health care needs resulting in ill-equipped graduates. A mismatch of student competency to population health needs, a narrow technical focus that fails to account for a broader contextual understanding of healthcare, and a focus on hospital orientated health education are factors that impact on student capacity to respond to changing and complex healthcare environments (Frenk et al., 2010). Additional research is required to determine if participation in the program provides participants with skills that are transferable across health care contexts and are of relevance to the health industry.

\section{Theme 5: Program implications}

This theme contains two sub-themes: program implications for Universities and program implications for students and associated subsections.

\section{Sub-theme 1: University implications}

This subtheme has two subsections: curriculum and model transferability.

\section{Subsection1: Curriculum development}

The MA reported that program participation had influenced faculty investment in rural curriculum content:

In order to prepare the students for that remote experience we need to put rural health in the curriculum so that when they go to the community they've got a bit of an idea. That's made us backtrack to our curriculum and up the rural content.

\section{Subsection 2: Model transferability.}

Student participants discussed the potential transferability of the program and implications for their universities:

This program could be fed back to our universities to help them with some of the school placements they try and run because this is far more organised. (FG2:S4) 
The MA identified their perceptions of impact on faculty in considering transferability of the model to other contexts:

One of the things the program has done, because that clinical education model has been so successful, is stimulated the thinking of [faculty] staff around using similar models in other places, helping other organisations to use those kinds of models. To develop different models that launch from here [into metropolitan sites].

Wakerman et al. (2009) identified that rural communities are incubators of health service and workforce innovations that better meet the needs of these communities. Denser connections within rural communities increase opportunities to implement change at the population level. The transferability of rural health service and workforce innovation into metropolitan contexts is poorly understood and additional research is required that explores the transferability and impact of rurally developed models in these locations.

\section{Sub-theme 2: Student implications}

The students identified four aspects of the program for further consideration: Impact on care delivery, longer placements, intent for rural practice and return to previous placement experiences.

Concerns were raised by students about their contribution to health care outcomes in previous experiences:

In other placements you just go in and go out and you don't really feel like you've made a difference. ... Here in this continuum of students you really do feel like you're at least making some change [for the pupil]. (FG1 S2)

Length of placement experience was identified by many of the students as a factor that impacted on consolidation of their knowledge and skills:

This week I will just feel as if I'm getting into it, getting the hang of things. ...I feel like an additional [placement] month, in terms of the development for the children, would change [pupil outcomes] dramatically within that month. (FG2:S3)

Students had differing views on how the placement might influence their consideration of rural practice post-graduation:

I would consider [working rurally] definitely. After this placement I probably would consider it. (FG1:S2)

For me personally I wouldn't go rural straight away because of the lack of support first year out. I think I need that support. (FG1:S5)

The difficulty of returning to highly supervised placements was also raised:

I'm thinking it might be difficult to go back to a traditional placement, being supervised all the time and [loosing autonomy]. (FG1:S2)

Experiential learning includes student engagement in tasks that are aligned to healthcare provision, including the direct engagement of students with healthcare recipients. Through this engagement students are provided with a deeper insight into the role of health professionals and their contribution to improved health outcomes (Spiers \& Harris, 2015). Experiencing a sense of professional satisfaction through direct service provision to clients has been identified as improving student participation and learning outcomes (Suchman et al., 2011). The time required to enable students to gauge their impact on care requires sustained engagement over a period of time (Herrington \& Herrington, 2006). Benefits associated with longer duration of student placements have been explored in the health education literature, predominately within medical student education (Forster, Assareh, Watts, \& McLachlan, 2013). Opportunities to extend allied health student placements within 
rural locations needs to be explored to enable the consolidation of student learning and service recipient outcomes.

\section{Discussion Summary}

A high level of connectivity exists across the themes, subthemes and subsections discussed in this paper. Addressing rural health workforce and service accessibility challenges is complex. Of equal complexity is the development and delivery of quality WIL experiences in these locations. Allied health students and academics described a number of broad challenges that can be experienced in the provision of WIL and IPP experiences. Student descriptions of previous placements, 'shadows' and 'shadowing', raise a number of concerns associated with the active engagement of students in 'real world' work of 'real meaning' in 'real world' contexts. If WIL strategies are to uphold 'the promise of producing graduates with the capabilities valued by employers' (Smith et al. 2014, p.14) additional investments are required to ensure these experiences meet WIL and industry objectives.

Study participants identified a number of beneficial learning outcomes acquired through their participation in the program including insight into rural community contexts, complex and interconnected relationships, planning and organisation skills and enhanced self-confidence. Findings suggest that a rural CBISL experience has the potential to impact on student acquisition of work-readiness attributes and the practices of a metropolitan university.

\section{Limitations}

The small participant sample size associated with this qualitative study limits generalisability of the results. Findings are representative of one student cohort and a small number of academics. Additional research is required to explore program impact on greater numbers of participating students and academics. Comparative studies are also required that explore learning outcomes between program participants and non-participating peers. Servicelearning is inherently concerned with experiences of service recipients and communities and additional research is required on program outcomes for service recipients, pupils and families, school teaching staff, and local clinicians. Findings on community leader and agency perspectives are described in subsequent papers.

\section{Conclusion}

Universities and the health industry acknowledge the need to develop highly skilled workready health professionals. Levels of industry dissatisfaction with the current levels of workreadiness of Australian graduates have influenced the development of WIL strategies that seek to enhance student acquisition of generic skills. Limited evidence exists on the impact and outcomes of participation in WIL strategies for health students, higher education institutions and the health industry. This paper explored the impact on allied health student and academic participants in a rural CBISL program. The program aligned student learning to direct service provision to address unmet allied health needs of pre-school and primary school children in far west NSW, expanding student placement capacity within the region and exposing students to alternative learning and service provision approaches. Based on the findings of this study, CBISL, a relatively new educational pedagogy in Australian health education, may provide students, universities and the health industry with an additional approach that can contribute to the development of generic work-readiness attributes. The provision of WIL learning experiences that expose students to 'real work' in 'real world' settings that are of 'real value' to 'real rural communities' is imperative if we are to ensure a competent future health workforce. 


\section{Acknowledgements}

The authors wish to acknowledge NSW Department of Education and Communities primary schools, Catholic Education primary schools, and pre-schools located in far west NSW who are engaged in the program. Funding for the ongoing development of the study program was accessed through Health Workforce Australia. The University of Sydney, Faculty of Health Sciences was the foundational university to engage in this program. The University of Sydney, Broken Hill University Department of Rural Health, is a federally funded program through the Commonwealth Department of Health. 


\section{References}

Australian Interprofessional Practice and Education Network. Online glossary. Retrieved from http://www.aippen.net/what-is-ipe-ipl-ipp

Allied Health Professionals Australia. (2013). Policy paper: Australia's workforce of allied health professionals. Canberra: AHPA.

Arum, R. \& Roksa, J. (2011). Academically adrift: Limited learning on college campuses. Chicago: University of Chicago Press.

Cashman, S. \& Seifer, S. (2008). Service-learning: An integral part of undergraduate public health. American Journal of Preventative Medicine, 35(3), 273-278.

Creswell, J. (2007). Qualitative inquiry and research design: Choosing among five approaches $\left(2^{\text {nd }}\right.$ ed.). London: Sage Publications.

Deaville, J. \& Grant, A. (2011). Overcoming the pull factor of convenient urban-livingPerceptions of rural practice. Medical Teacher. 33: e11-e217.

Department of Industry, Innovation, Science, Research \& Tertiary Education (DIISRTE), and Department of Education, Employment and Workplace Relations (DEEWR). (2013). Core Skills for Work Framework. Canberra: Commonwealth of Australia.

Department of Health and Aging (DoHA). (2010). National Primary Health Care Strategic Framework. Canberra: Commonwealth of Australia.

Durning,S., Artino, A., Pangaro, L., van der Vleuten, C., \& Schuwirth, L. (2011). Context and clinical reasoning. Advances in Health Science Education, 45(9), 927-938.

Eyler, J. \& Giles, D. (1999). Where's the learning in service-learning? San Francisco: Jossey-Bass

Forster, L., Assareh, H., Watts, L., \& McLachlan, C. (2013). Additional years of Australian Rural Clinical School undergraduate training is associated with rural practice. BMC Medical Education, 13(37). Retrieved from http://www.biomedcentral.com/1472$\underline{6920 / 13 / 37}$

Freeth, D., Hammick, M., Reeves, S., Koppel, I., \& Barr, H. (Ed.). (2005). Effective interprofessional education: Development, delivery \& evaluation. Oxford: Blackwell Publishing Ltd.

Frenk, J., Chen, L., Bhutta, Z., Cohen, J., Crisp, N., Evans, S., \& Zurayk, H. (2010). Health professionals for a new century: Transforming education to strengthen health systems in an interdependent world. The Lancet, 376(9756), 1923-1958 Retrieved from http://www.thelancet.com

Furco, A. (1996). Service-learning: A balanced approach to experiential education. Expanding boundaries: Service and learning. Washington DC: Corporation for National Service, 2-6.

Hartigan-Rogers, J., Cobbett, S., Amirault, M., \& Muise-Davis, M. (2007). Nursing graduates' perceptions of their undergraduate clinical placement. International Journal of Nursing Education Scholarship, 4(1), 1-14. 
Health Workforce Australia. (2013a). A Framework for Effective Clinical Placements in Rural and Remote Primary Health Care. Adelaide: HWA.

Health Workforce Australia. (2013b). National Rural and Remote Heath Workforce Innovation and Reform Strategy. Adelaide: HWA.

Herrington, T. \& Herrington, J. (Eds.). (2006). Authentic learning environments in higher education. Melbourne: Information Science Publishing.

Howell, D., Devine, N. \& Prostman, L. (2004). An interdisciplinary learning experience through applied clinical practice with community volunteers. Journal of Allied Health, 33(3), 205-209.

Jacoby, B. (Ed.). (2003). Building partnerships for service-learning. San Francisco: Wiley \& Sons.

Jackson, D. (2010). An international profile of industry-relevant competencies and skill gaps in modern graduates. International Journal of Management Education, 8(3), 29-8.

Jones, D., McAllister, L., Lyle, D., Brunero, C., Webb, T., \& Riley, S. (2015). Improving health and education outcomes for children in remote communities: A cross-sector and developmental evaluation approach. International Journal of Community Research and Engagement, 8(1), 1-22.

Keys, L. (1994). Action learning: Executive development of choice for the 1990's. Journal of Management Development, 13(8), 50-56.

Kindig, D. \& Stoddart, G. (2003). What is population health? American Journal of Public Health. 93(3), 380-383

Kolb, D. (1984). Experiential learning: Experience as the source of learning and development. Englewood Cliffs: Prentice Hall.

Kramer, M. \& Usher, A. (2011). Work-integrated learning and career-ready students: Examining the evidence. Toronto: Higher Education Strategy Associates.

Kuipers, P., Pager, S., Bell, K., Hall, F., \& Kendall, M. (2013). Do structured arrangements for multidisciplinary peer group supervision make a difference for allied health professional outcomes? Journal of Multidisciplinary Care, 6, 391-397.

McAllister, L. \& Rose, M. (2008). Speech-language pathology students: Learning clinical reasoning. In J. Higgs, M. Jones, S. Loftus, \& N. Christensen. (Eds.), Clinical Reasoning in the Health Professions, (397-404). Amsterdam: Elsevier.

McAllister, L., Paterson, M., Higgs, J., \& Bithell, C. (2010). (Eds.). Innovations in allied health fieldwork education: A critical appraisal. Boston: Sense Publishers.

Mason, J. (2013). Review of Australian government health workforce programs. Retrieved from:

https://www.health.gov.au/internet/main/publishing.nsf/Content/D26858F4B68834EACA 257BF0001A8DDC/\$File/Review\%20of\%20Health\%20Workforce\%20programs.pdf 
Miles, B., Huberman, M., \& Saldana, J. (2014). Qualitative data analysis: A methods sourcebook (3rd Edition). London: Sage Publications.

Miller, T. \& Gallicchio, V. (2007). Allied health professionals with 2020 vision. Journal of Allied Health, 36(4), 236-240.

Newton, J., Billet, S., Jolly, B., \& Ockerby, C. (2009a). Lost in translation: Barriers to learning in the health professional clinical education. Learning in Health and Social Care, 8(4), 315-327.

Nisbet, G., Lee, A., Kumar, K., Thistlethwaite, J., \& Dunston, R. (2011). Interprofessional health education. A literature review: Overview of international and Australian developments in interprofessional health education. University of Technology Sydney: Centre for Research in Learning and Change.

Norman, G. (2005). Research in clinical reasoning. Medical Education, 39(4), 418-427.

Patton, M. (2002). Qualitative research and evaluation ( $3^{\text {rd }}$ Ed.). London: Sage Publications.

Plack, M. (2008). The learning triad: Potential barriers and supports to learning in the physical therapy clinical environment. Journal of Physical Therapy Education, 22(3), 718.

Rodger, S., Webb, G., Devitt, L., Gilbert, J., Wrightson, P. \& McMeeken, J. (2008). Clinical education and practice placements in the allied health professions: An international perspective. Journal of Allied Health, 37(1), 53-62.

Rodger, S., Fitzgerald, C., Davila, W., Millar, F., \& Allison, H. (2011). What makes a quality occupational therapy practice placement? Students' and practice educators' perspectives. Australian Occupational Therapy Journal, 58(3), 195-202.

Seifer, S. (1998). Service-learning: Community-campus partnerships for health professions education. Academic Medicine, 73(3), 273-77.

Sharp, M., Reynolds, R., \& Brooks, K. (2013). Critical thinking skills of allied health science students. A structured inquiry. Educational Perspectives in Health Informatics and Information Management. 1-13. Retrieved from http://eduperspectives.ahima.org/critical-thinking-skills-of-allied-health-science-studentsa-structured-inquiry/\#.VTRNokOiN1s

Skills Australia. (2010). Australian workforce futures: A national workforce development strategy. Canberra: Commonwealth of Australia.

Smedley, A. \& Morey, P. (2010). Improving learning in the clinical nursing environment: perceptions of senior Australian bachelor of nursing students. Journal of Research in Nursing, 15(1), 75-88.

Smith, C., Ferns, S., \& Russell, L. (2014). The impact of work integrated learning on student work-readiness. Final Report 2014. Sydney: Office for Learning and Teaching.

Spiers, M. \& Harris, M. (2015). Challenges to student transition in allied health undergraduate education in the Australian rural and remote context: A synthesis of barriers and enablers. Rural and Remote Health, 15: 3069.retrieved from http://www.rrh.org.au/publishedarticles/article print 3069.pdf 
Steinberg, K., Bringle, R. \& Williams, M. (2010). Service-learning research primer. Scotts Valley: National Service-Learning Clearinghouse.

Steinke, P. \& Fitch, P. (2014). Using goal-based learning to understand why service-learning improves cognitive outcomes. Currents in Teaching and Learning, 7(1), 50-63.

Sturmberg, J. (2005). How to teach holistic care - Meeting the challenge of complexity in clinical practice. Education for Health, 18(2), 236-245.

Suchman, A, Sluyter, D., \& Williams, P. (Eds). (2011). Leading change in healthcare: Transforming organisations using complexity, positive psychology and relationshipcentered care. London: Ratcliffe Publishing.

Titchen, A. \& Higgs, J. (2001). A dynamic framework for the enhancement of health professional practice in an uncertain world: The practice knowledge interface. In $\mathrm{J}$. Higgs \& A. Titchen (Eds.), Practice knowledge and expertise in the health professions. (215-225), Oxford: Butterworth Heinemann.

Wakerman, J., Humphreys, J., Wells, R., Kuipers, P., Jones, A., Entwistle, P., \& Kinsman, L. (2009). Features of effective primary health care models in rural and remote Australia: A case-study analysis. Medical Journal of Australia, 191, 88-91.

Walker, A., Yong, M., Pang, L., Fullarton, C., Costa, B., \& Dunning, T. (2013). Work readiness of graduate health professionals. Nurse Education Today, 33, 116-122.

World Health Organisation (WHO). (2010). Framework for action on interprofessional education and collaborative practice. Geneva: Health Professions Networks Nursing \& Midwifery Human Resources for Health. (WHO/HRH/HPN/10.3). Retrieved from http://www.who.int/hrh/nursing midwifery/en/

Wylie, K., McAllister, L., Marshall, J., \& Law, J. (2014). Adopting public health approaches to communication disability: Challenges for the education of speech-language pathologists. Folia Phoniatr Logop; 66, 164-175. Education for Communication Disability Public Health. 